\title{
Konflik Batin Tokoh Sasaki Miyo Dalam Anime Nakitai Watashi Wa Neko Wo Kaburu
}

\author{
Nurul Annisa Sabrina \\ Program Studi Sastra Jepang, Universitas Jenderal Soedirman, Indonesia \\ e-mail: nurul.sabrina@mhs.unsoed.ac.id
}

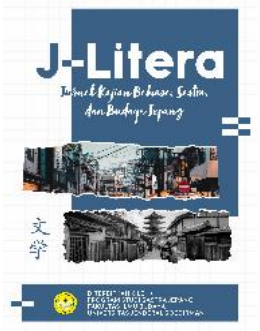

\begin{abstract}
This research examines the intrinsic elements of anime Nakitai Watashi wa Neko wo Kaburu, as well as the inner conflicts and defense mechanisms of Sasaki Miyo character in the anime Nakitai Watashi wa Neko wo Kaburu. This research uses qualitative descriptive technique with literary psychology approach. The data collection technique was carried out by using the note-taking technique. The theories that were used in this research are fiction study theory to analyze intrinsic elements and Freud's psychoanalytic theory to analyze the inner conflict and defense mechanisms of Sasaki Miyo. The result of this research is that there are 35 data that show the intrinsic elements of the anime Nakitai Watashi wa Neko wo Kaburu and 8 data that show the inner conflict and defense mechanisms of Sasaki Miyo character in the anime Nakitai Watashi wa Neko wo Kaburu. The conclusion that can be drawn from this research is that Sasaki Miyo, a middle school girl who was unhappy because her parents had gotten divorced and chose to run away from her house as a cat, experienced inner conflicts and used various defense mechanisms when the inner conflicts occurred. There are 6 defense mechanisms that are used by Miyo, and those are reaction formation, rationalization, reversal, compensation, and undoing. The factors that cause Miyo's unhappiness eventually accumulated so that Miyo often used projection as a defense mechanism, where she continued to project her anger towards her parents.
\end{abstract}

Keywords:

Intrinsic elements; Literary psychology; Psychoanalysis; Inner conflict; Defense

mechanisms

Article Info:

First received:

2 February 2021

Available online:

28 May 2021

\section{PENDAHULUAN}

Salah satu bentuk karya sastra adalah Anime. Kata anime (アニメ) adalah istilah Jepang untuk animasi, yang berarti semua bentuk media animasi. Anime dibuat oleh orang Jepang dengan berbagai macam fungsi. Selain sebagai produk untuk hiburan, anime sendiri sudah menjadi bagian dari budaya Jepang. Anime bisa juga dianggap sebagai karya sastra tergantung dari bahasa yang digunakan dalam dialog pada anime tersebut. Karena anime bisa dianggap sebagai karya sastra, maka dalam anime sendiri bisa dilihat unsur instrinsik dan kondisi psikologis tokohnya.

Penulis bermaksud menganalisis konflik batin yang dialami oleh tokoh utama dalam anime yang berjudul "Nakitai Watashi wa Neko wo Kaburu" yang bernama Sasaki Miyo dengan menggunakan teori psikoanalisis klasik oleh Sigmund Freud.
Berkisah tentang seorang gadis sekolah menengah, Sasaki Miyo, yang menjalani kehidupan sehari-harinya merasa tidak bahagia karena orang tuanya yang bercerai dan harus tinggal bersama ibu tirinya. Pada saat pergi ke sebuah festival bersama ibu kandungnya, Miyo bertemu dengan penjual topeng misterius yang menawarkan sebuah topeng yang dapat mengubah manusia menjadi kucing jika memakai topeng tersebut. Miyo yang kemudian berubah menjadi kucing memanfaatkan kesempatan tersebut untuk mendekati teman sekelasnya, Hinode Kento. Hinode yang tidak tahu bahwa kucing yang ditemuinya adalah Miyo, memberi nama kucing tersebut Taro.

Suatu hari karena merasa muak dengan keluarganya, Miyo memutuskan untuk kabur dari rumah sebagai Taro dan berkata pada Si Kucing Penjual kalau Miyo ingin menjadi kucing sepenuhnya saja. Tidak lama setelah itu, Miyo menyesali keputusannya untuk berubah 
menjadi kucing dan berharap agar dia dapat merujuk Si Kucing Penjual agar mengembalikan wajah manusianya lagi. Miyo pergi ke Pulau Kucing dan dengan bantuan Hinode dan para manusia setengah kucing lainnya, dia berhasil mendapatkan wujud manusianya kembali.

Tokoh Miyo mengalami konflik batin dan melakukan salah satu strategi mekanisme pertahanan (defense mechanism) dalam bentuk projeksi demi mengurangi penderitaan yang dialaminya dengan cara melibatkan dorongan rasa marahnya kepada orang lain dan dunia luar, dan hal tersebut dapat dianalisis menggunakan teori psikoanalisis yang dikembangkan pertama kali oleh Sigmund Freud dan dapat diperkuat dengan teori lain tentang psikoanalisis yang mendukung teori Freud, serta dengan meneliti unsur instrinsik anime tersebut.

Berdasarkan rumusan masalah di atas, tujuan penelitian ini adalah mendeskripsikan unsur instrinsik yang ada pada anime Nakitai Watashi wa Neko wo Kaburu dan mendeskripsikan konflik tokoh Sasaki Miyo dalam anime Nakitai Watashi wa Neko wo Kaburu.

\section{TINJAUAN PUSTAKA}

\section{Unsur Instrinsik}

Unsur instrinsik menurut Nurgiyantoro (2009: 23) adalah: "unsur-unsur yang membangun karya sastra itu sendiri." Jika diibaratkan, unsur instrinsik itu seperti pilarpilar yang jika digabungkan membentuk sebuah bangunan. Secara totalitas, unsur-unsur intsrinsik dari karya sastra tergabung menjadi sebuah karya sastra secara utuh.

Jika ingin mengkaji suatu karya sastra, maka penting untuk mengetahui apa saja unsur instrinsik karya sastra tersebut. Selain untuk memudahkan proses penelitian, dengan menentukan unsur instrinsik, argumen bisa lebih diperkuat.

\section{Tema}

Stanton (Nurgiyantoro 2009: 70), mengartikan tema sebagai "makna sebuah cerita yang secara khusus menerangkan sebagian besar unsurnya dengan cara yang sederhana."

\section{Plot}

Menurut Nurgiyantoro (2009: 116), ada tiga unsur penting yang menentukan ekstensi plot itu sendiri, yaitu peristiwa, konflik, dan klimaks. Pembedaan plot berdasarkan kriteria waktu dapat dilakukan dengan melihat apakah plot tersebut bersifat progresif atau regresif, di mana plot progresif adalah plot yang dari awal kejadian bersifat kronologis atau peristiwa dari tahap awal sampai akhir berurutan, sementara plot regresif adalah plot yang tak kronologis atau plot yang pada tahapan awal cerita dimulai dari bagian klimaks atau bagian tengah (Nurgiyantoro, 2009: 154).

\section{Penokohan}

Menurut Nurgiyantoro (2009: 116), ada tiga unsur penting yang menentukan ekstensi plot itu sendiri, yaitu peristiwa, konflik, dan klimaks. Pembedaan plot berdasarkan kriteria waktu dapat dilakukan dengan melihat apakah plot tersebut bersifat progresif atau regresif, di mana plot progresif adalah plot yang dari awal kejadian bersifat kronologis atau peristiwa dari tahap awal sampai akhir berurutan, sementara plot regresif adalah plot yang tak kronologis atau plot yang pada tahapan awal cerita dimulai dari bagian klimaks atau bagian tengah (Nurgiyantoro, 2009: 154).

\section{Latar}

Latar menurut Abrams (Nurgiyantoro, 2009: 216) adalah "landasan atau tumpuan yang memiliki pengertian tempat, hubungan waktu, dan lingkungan sosial tempat terjadinya peristiwa-peristiwa yang diceritakan."

\section{Sudut pandang}

Sudut pandang menandakan cara cerita diceritakan, atau lebih tepatnya, sudut pandang adalah perspektif yang ditetapkan oleh seorang penulis di mana pembaca akan disajikan cerita dengan karakter, tindakan, latar, dan peristiwa yang merupakan narasi dalam sebuah karya fiksi (Abrams, 1988: 144).

\section{Gaya bahasa}

Gaya bahasa merupakan cara pengucapan atau cara penulis mengungkapkan sesuatu yang dia maksud (Abrams, 1981: 190-1 via Nurgiyantoro, 2009: 276). 


\section{Amanat}

Nurgiyantoro dalam bukunya (2009: 321) menjelaskan bahwa moral dalam karya sastra dapat dipandang sebagai amanat, pesan, message. Jadi pesan atau nilai moral yang dapat diambil dalam sebuah cerita adalah amanat.

\section{Teori Psikoanalisis}

Psikoanalisis adalah ilmu yang mulai dikembangkan sekitar awal abad ke-20 oleh neurologis dari Austria, Sigmund Freud. Menurut Minedrop (2010: 11): "Teori psikoanalisis berhubungan dengan fungsi dan perkembangan mental manusia."

Menurut Davey (2012: 10), Freud mengklaim bahwa pikiran terdiri dari tiga bagian, yaitu pikiran sadar, sadar dan tak sadar.

Baru pada awal abad ke-20, Freud mengenalkan tiga konsep struktural yang lain, yaitu id, ego, dan superego. Alwisol dalam bukunya (Alwisol, 2018: 15), menyatakan bahwa "struktur baru ini tidak mengganti struktur lama, tetapi melengkapi gambaran mental terutama dalam fungsi atau tujuannya."

\section{Id}

Id adalah bagian dari pikiran yang mengandung dorongan yang hadir sejak saat lahir; dengan kata lain sumber dari kebutuhan, keinginan, hasrat, dan impuls tubuh kita, terutama dorongan seksual dan agresif kita (Schacter, 2010: 481).

\section{Ego}

Menurut Schacter (2010: 481), Ego adalah komponen kepribadian yang dikembangkan melalui kontak dengan dunia luar, yang memungkinkan kita untuk menghadapi kehidupan nyata.

\section{Superego}

Alwisol (2018: 18) menjelaskan bahwa Superego adalah moral dan etika dari kepribadian yang dimiliki seseorang dan beroperasi memakai prinsip idealistis di mana akan bertentangan dengan Id yang memiliki prinsip kepuasan.

Mekanisme pertahanan adalah strategi yang digunakan oleh sesorang yang berfungsi untuk mengurangi kecemasan yang dihasilkan oleh ancaman dari impuls yang tidak dapat diterima atau dianggap akan memunculkan ancaman yang lebih besar (Schacter, 2010: 482).

Pada penelitian ini, terdapat 6 mekanisme pertahanan yang dilakukan oleh Miyo, yaitu projeksi, reaction formation, rasionalisasi, reversal, kompensasi, dan undoing.

\section{Projeksi}

Projeksi adalah mekanisme pertahanan yang melibatkan hubungkan perasaan, motif, atau dorongan impuls seseorang yang mengancam kepada orang atau kelompok lain (Schacter, 2010: 482).

\section{Reaksi Formasi}

Pembentukan reaksi adalah sebuah mekanisme pertahanan di mana secara tidak sadar sesorang akan menggantikan keinginan dan fantasi yang mengancam dengan melakukan hal yang berefek kebalikannya secara berlebihan, seperti bertingkah baik dengan orang yang tidak disukai (Schacter, 2010: 482).

\section{Rasionalisasi}

Rasionalisasi adalah penerimaan dan rasa puas yang didasari oleh hal yang rasional dan masuk akal (Alwisol, 2018: 31).

\section{Reversal}

Pembalikan atau reversal adalah perubahan ego yang aktif menjadi pasif, atau lebih tepatnya dorongan impuls yang mengancam kepada orang lain diubah kearah diri sendiri (Alwisol, 2008: 30).

\section{Kompensasi}

Kompensasi adalah mekanisme pertahanan yang melibatkan penyaluran atau pemindahan dorongan dengan cara mengganti impuls dorongan yang dimilikinya (Alwisol, 2018: 28). 


\section{Undoing}

Undoing adalah mekanisme pertahanan di mana aksi yang buruk digantikan dengan aksi yang lebih baik karena perasaan bersalah (Alwisol, 2018: 31).

\section{METODE PENELITIAN}

Penelitian ini merupakan penelitian deskriptif kualitatif. Bogdan dan kawan-kawan (2015: 7) menyatakan: "The phrase qualitative methodology refers in the broadest sense to research that produces descriptive data-people's own written or spoken words and observable behavior."

\section{Teknik Pengumpulan Data}

Teknik pengumpulan data dalam penelitian ini adalah menggunakan teknik simak dan teknik catat. Karena objek penelitian ini anime, maka penulis menyimak semua dialog yang dilakukan tokoh-tokoh yang terdapat dalam anime Nakitai Watashi wa Neko wo Kaburu. Setelah teknik simak dilakukan, maka langkah selanjutnya adalah penulis mencatat hasil penyimakan berupa dialog yang menunjukkan konflik batin serta kondisi psikologis oleh tokoh Sasaki Miyo dalam anime Nakitai Watashi wa Neko wo Kaburu.

\section{Teknik Analisis Data}

Peneliti akan menggunakan data yang telah dikumpulkan dan menganalisisnya dengan menggunakan metode analisis pendekatan teori struktural Burhan Nurgiyantoro dan pendekatan psikoanalis Sigmund Freud. Pada penelitian ini ada dua permasalahan yang diteliti, yaitu unsur instrinsik film serta konflik batin dan mekanisme pertahanan tokoh utamanya.

\section{Teknik Penyajian Data}

Penyajian analisis data yang digunakan oleh penulis adalah menggunakan metode informal. Dengan metode ini penulis mengharapkan mampu menyajikan hasil analisis data dan pembaca dapat memahaminya dengan mudah.

\section{HASIL PENELITIAN}

Pada bagian ini akan disajikan hasil penelitian dan pembahasan bagaimana unsur instrinsik yang ada pada anime Nakitai Watashi wa Neko wo Kaburu dan mendeskripsikan konflik batin dan mekanisme pertahanan tokoh Sasaki Miyo dalam anime Nakitai Watashi wa Neko wo Kaburu.

\section{Unsur Instrinsik}

\section{Plot}

Menurut Nurgiyantoro, pembedaan plot berdasarkan kriteria waktu dapat dilakukan dengan melihat apakah plot tersebut bersifat progresif atau regresif, di mana plot progresif adalah plot yang dari awal kejadian bersifat kronologis atau peristiwa dari tahap awal sampai akhir berurutan, sementara plot regresif adalah plot yang tak kronologis atau plot yang pada tahapan awal cerita dimulai dari bagian klimaks atau bagian tengah. Pada anime Nakitai Watashi wa Neko wo Kaburu bisa dikaji jenis plotnya dengan melihat data-data yang terkumpul. Miyo pertama kali bertemu dengan Si Kucing Penjual yang menawarkannya topeng kucing. Dari situ, alur cerita dimulai. Miyo yang sudah muak dengan hidupnya berkata kalau dia lebih baik menjadi kucing saja seterusnya. Permasalahan atau konflik sudah bertumpuk dan terus menuju ke bagian klimaks, di mana Miyo menyesali keputusannya untuk berubah menjadi kucing dan berusaha untuk kembali merebut identitas manusianya. Para manusia setengah kucing yang membantu Miyo dan Hinode melawan Si Kucing Penjual, yang pada akhirnya Miyo kembali mendapatkan wajah manusianya.

Berikut adalah contoh pembahasan yang dilakukan peneliti dalam menganalisis unsur instrinsik anime Nakitai Watashi wa Neko wo Kaburu serta konflik batin dan mekanisme pertahanan tokoh Sasaki Miyo. Dalam analisis unsur instrinsik, peneliti mengambil contoh tokoh dan penokohan. Sementara pada analisis mekanisme pertahanan Sasaki Miyo, peneliti mengambil contoh projeksi dan kompensasi.

\section{Tokoh dan Penokohan}

Anime Nakitai Watashi wa Neko wo Kaburu terfokuskan pada tokoh Sasaki Miyo.

\section{A. Tokoh Sasaki Miyo}


Sasaki Miyo adalah tokoh utama dalam anime Nakitai Watashi wa Neko wo Kaburu. Secara keseluruhan, plot atau jalan cerita dalam anime Nakitai Watashi wa Neko wo Kaburu menggambarkan bagaimana tokoh Sasaki Miyo menghadapi masalahnya dengan keluarga dan teman-temannya.

a) Susah ditebak

Susah ditebak merupakan salah satu watak Sasaki Miyo yang dideskripsikian oleh temantemannya di sekolah. Miyo sendiri terkenal dengan panggilan "Muge" yang dalam Bahasa Jepang merupakan kependekan dari kata "Mugendai Nazo Ningen" yang artinya adalah "Manusia Misterius Tanpa Batas" karena perilakunya yang tak terkendali.

\section{b) Bertingkah tegar}

Miyo digambarkan kalau dia sering bertingkah kalau dia baik-baik saja meskipun sebenarnya dia menderita. Hal tersebut membuat dirinya selalu terlihat ceria. Miyo sendiri mengakui kalau ada banyak hal yang sulit dia ungkapkan, namun dia lebih memilih menyembunyikannya dengan selalu bertingkah tegar atau ceria.

Sementara itu, Yoriko sebagai teman terdekat Miyo juga mendeskripsikan Miyo sebagai orang yang suka bertingkah tegar meskipun sedang menderita.

\section{Tema}

Dari keseluruhan alur cerita film anime Nakitai Watashi wa Neko wo Kaburu, bisa diketahui ada beberapa permasalahan atau topik yang diambil di dalamnya, seperti (1) Hubungan Miyo dengan kedua orang tuanya yang bercerai dan harus tinggal bersama ayah dan ibu tirinya, (2) Sifat Miyo yang sulit ditebak di sekolah yang membuat dia mengalami permasalahan dengan anak-anak yang menjahilinya, (3) Usaha Miyo dalam menyampaikan perasaannya kepada Hinode, (4) Miyo yang akhirnya menyerah dan memilih kabur dari rumah sebagai kucing, namun menyesali keputusannya setelah itu, (6) Si Kucing Penjual yang menipu Miyo dan berusaha mengambil umur Miyo hingga Miyo terancam berubah menjadi kucing selamanya.
Dari berbagai permasalahan yang terlampir di atas, bisa dibilang bahwa seluruh permasalahan tersebut saling berhubungan menjadi sebuah cerita dan dari situ dapat dilihat tema pokok dari cerita tersebut. Yang menjadi tema atau gagasan pokok anime Nakitai Watashi wa Neko wo Kaburu adalah kisah Miyo, seorang gadis SMP yang tidak bahagia memilih untuk lari dan berubah menjadi kucing.

Anime Nakitai Watashi wa Neko wo Kaburu sendiri menceritakan Miyo yang lari dari rumahnya sebagai kucing karena dia sudah muak dengan situasinya dengan keluarganya dan juga merasa sedih setelah Hinode, anak lakilaki yang disukainya, mengatakan kalau dia benci dengan Miyo. Sementara itu, Hinode juga mengalami situasi yang hampir sama di mana dia tidak bisa berkata apapun dengan keluarganya mengenai apa yang dia inginkan. Miyo dan Hinode memiliki masalah yang familier di mana keduanya diceritakan bahwa mereka memilih untuk diam dan lari dari situasi yang tidak disukainya, hingga pada akhirnya Miyo yang mendapatkan topeng kucing saat malam Festival Tenno memilih untuk menjadi kucing, namun menyesali keputusannya setelah itu.

\section{Latar}

Latar pada suatu karya dapat dibagi menjadi 3, yaitu latar tempat, latar waktu, dan latar sosial.

\section{A. Latar tempat}

Pada anime Nakitai Watashi wa Neko wo Kaburu, latar tempat berada di Tokoname, Prefektur Aichi, Jepang. Direktur film animasi Nakitai Watashi wa Neko wo Kaburu sendiri memang berencana untuk membuat film ini berdasarkan masa kecilnya saat berada di kota tersebut, sehingga dalam anime Nakitai Watashi wa Neko wo Kaburu banyak ditemukan pemandangan yang digambarkan sesuai dengan tempat aslinya di kota tersebut.

\section{B. Latar Waktu}

Latar waktu dalam anime Nakitai Watashi wa Neko wo Kaburu terjadi pada saat musim panas. Hal tersebut bisa dilihat dari awal film di mana Miyo pergi merayakan Festival Tenno di Kota Tokoname bersama ibunya. 


\section{Latar Sosial}

Latar sosial pada anime Nakitai Watashi wa Neko wo Kaburu ditunjukkan oleh pandangan sosial maupun kepercayaan yang ada pada karakter dalam anime itu sediri. Berikut latar sosial yang ada pada anime Nakitai Watashi wa Neko wo Kaburu:

a) Kebiasaan Orang Jepang merayakan festival musim panas

Kebiasaan Orang Jepang dalam ikut merayakan berbagai macam festival pada saat musim panas terlihat dalam anime Nakitai Watashi wa Neko wo Kaburu. Pada awal cerita, Miyo pergi bersama ibunya ke sebuah festival musim panas, dan meskipun Miyo sedang marah pada ibunya saat itu, dia tetap ikut memainkan salah satu permainan yang ada pada festival tersebut seperti permainan mengambil ikan dengan alat khusus.

b) Masih mengandalkan anak laki-laki untuk menafkahi keluarga

Salah satu latar sosial dalam anime Nakitai Watashi wa Neko wo Kaburu adalah bagaimana beberapa orang tua di Jepang masih ada yang percaya kalau anak laki-laki harus bisa diandalkan untuk ikut berkontribusi dalam menafkahi keluarganya. Hal tersebut digambarkan oleh Sachiko, ibunya Hinode, saat ia memarahi Hinode karena Hinode belum mengumpulkan lembar formulir pendaftaran SMAnya.

\section{Konflik batin Sasaki Miyo}

Konflik batin adalah dinamika yang terjadi antara id, ego dan superego. Konflik batin yang dialami tokoh Sasaki Miyo bisa dilihat dari bagaimana dinamika antara Id, Ego, dan Superego dari tokoh Sasaki Miyo bekerja. Mekanisme pertahanan yang dilakukan oleh tokoh Sasaki Miyo dalam menangani konflik batin yang dialaminya bisa dilihat dari dialog atau tindakan yang dilakukan olehnya.

\section{Projeksi dan Reversal}

Seperti yang diketahui bahwa pada awal cerita, Miyo mengalami konflik batin di mana dirinya tidak suka dengan orang tuanya yang bercerai dan harus tinggal bersama ibu tirinya.
Pada saat pergi bersama ibu kandungnya ke sebuah festival, Miyo melakukan projeksi demi mengurangi penderitaan yang dialaminya dengan cara melibatkan dorongan rasa marahnya kepada orang lain dan dunia luar

Perasaan marah Miyo pada orang tuanya yang baru saja bercerai dan menyebabkan ibunya meninggalkannya merupakan bagian dari Id atau dorongan yang dimilikinya. Saat ibunya mencoba menjelaskan kalau ada beberapa hal yang anak kecil susah dimengerti, tuturan ibunya tersebut merupakan bagian dari superego. Miyo justru berlari kabur dari ibunya sambil mengatakan bahwa dirinya benci dengan dunia dan berharap kalau dunia hancur saja. Hal tersebut menunjukkan bahwa ego memilih untuk membela diri terhadap impuls dengan memprojeksikan impuls atau Id kepada objek lain, yaitu dunia luar. Tindakan Miyo tersebut merupakan sistem pertahanan projeksi.

Pada saat Kaoru menanyakan kenapa Miyo terus memaksakan dirinya bersikap senang, Miyo yang awalnya bersikap passive dengan melakukan reaksi formasi agar menjauhkan dirinya dari impuls yang berbahaya akhirnya menggantikan sikapnya di situasi yang sama dengan memprojeksikan amarahnya kepada Kaoru dan ayahnya yang kemudian ikut masuk ke kamar Miyo.

Miyo yang pada akhirnya memprojeksikan amarahnya terhadap Kaoru. Miyo mengakui kalau dirinya memang terpaksa tersenyum dan dia juga mengatakan kalau dirinya jelas tak akan suka degan kehadiran Kaoru. Dari dialog tersebut menunjukkan Id Miyo dengan jelas, yaitu dorongan amarahnya pada kedua orang tuanya yang dianggap egois dan juga ketidaksukaannya pada Kaoru. Pada saat ini Miyo yang awalnya melakukan reaksi formasi di mana dia bersikap ramah terhadap Kaoru akhirnya bersikap kebalikannya, di mana dia akhirnya berhenti bersikap ramah dan mengutarakan dorongan amarahnya. Tindakan tersebut merupakan gabungan mekanisme pertahananan berupa reversal dan projeksi.

\section{Pembuatan Reaksi}


Setiap berhadapan dengan Kaoru, Miyo sering kali mencoba untuk tertawa dan bersikap ramah agar dirinya terlihat seolah tidak ada masalah, meskipun sebenarnya dia tidak senang dengan situasi keluarganya pada saat itu. Karena itu, Kaoru berpikir bahwa sikap Miyo itu sebenarnya dipaksakan. Kaoru yang menduga kalau Miyo selama ini seakan memaksakan dirinya untuk tersenyum meskipun sebenarnya Miyo mungkin tidak suka dengan kehadiran Kaoru di rumahnya. Sebelumnya bisa dilihat Id Miyo yang merupakan dorongan marahnya karena orang tuanya yang bercerai dan dia menganggap mereka egois. Hal tersebut juga membuatnya tidak suka dengan Kaoru yang ikut tinggal di rumahnya, namun Miyo selalu bersikap ramah pada Kaoru walaupun terpaksa. Hal tersebut menunjukkan egonya yang melakukan tindakan defensif terhadap id yang dianggap membahayakan. Miyo merasa kalau dirinya bersikap dingin dengan Kaoru akan menimbulkan masalah, maka dari itu dia melawan id atau impulsnya yang membahayakan tersebut dengan tindakan kebalikannya, yaitu bersikap terlalu ramah kepada Kaoru. Tindakan tersebut merupakan mekanisme pertahanan reaction formation di mana dia bersikap berkebalikan terhadap sesuatu yang tidak disukainya.

\section{Rasionalisasi}

Miyo selalu ingin untuk mengungkapkan perasaannya kepada Hinode, namun saat Si Kucing Penjual menyarankan untuk memberi tahu kalau Miyo adalah Taro, Miyo menolak saran tersebut dan mengatakan bahwa lebih baik dia menyamar sebagai Taro terlebih dahulu untuk mengumpulkan informasi. Id Miyo dalam situasi ini adalah keinginannya untuk lebih dekat dengan Hinode, namun egonya merasa puas dan menekan kateksis atau energi psikis yang mendorong impulsnya tersebut dengan cara mengembangkan sebuah alasan rasional. Hal tersebut menunjukkan sebuah mekanisme pertahanan yang berupa rasionalisasi.

\section{Kompensasi}

Setelah Miyo lari dari rumahnya sebagai Taro dan datang mengunjungi Hinode, Miyo merasa kalau dirinya akan lebih disayang oleh Hinode sebagai Taro. Kemudian Miyo mengatakan kalau dirinya sudah muak sebagai Miyo. Pada saat ini, Miyo secara sadar atau tidak sadar menutupi rasa frustrasinya sebagai Miyo dan dorongan lain yang dapat menutupi rasa frustrasi tersebut, yaitu menjadi kucing, muncul. Kompensasi dapat menutupi kekurangan yang besifat nyata maupun tidak nyata dan juga menutupi rasa inferioritas pribadi atau fisik. Dengan begitu, saat wajah manusia Miyo terlepas karena dia sudah tidak ingin menjadi manusia lagi, dia melakukan kompensasi sebagai mekanisme pertahanan.

\section{Undoing}

Pada bagian akhir film, Miyo menyesali pilihannya untuk menjadi kucing dan mencoba untuk kembali menjadi manusia. Hal tersebut bisa dilihat dari bagaimana Miyo berusaha mencari Si Kucing Penjual dan pergi ke pulau kucing. Miyo menyesali keinginannya untuk berubah menjadi kucing berusaha untuk mencari Si Kucing Penjual demi kembali menjadi manusia. Lalu saat berada di Tempat Perjanjian dan melihat Hinode yang tengah melawan Si Kucing Penjual demi menolong Miyo yang diambil umurnya, Miyo sadar dan ingin memperbaiki semua kesalahannya. Miyo akhirnya mengakui kalau selama ini dia salah akan perasaannya yang negatif terhadap keluarganya, dan dia harus bertindak dan kembali menjadi Miyo untuk membenarkan kesalahannya. Pada saat itu Miyo melakukan undoing sebagai mekanisme pertahanan di mana dia melakukan tindakan baik atau positif demi menutupi tindakan buruk yang dia lakukan sebelumnya.

\section{KESIMPULAN}

Bisa ditarik kesimpulan bahwa plot atau alur yang digunakan dalam film anime Nakitai Watashi wa Neko wo Kaburu adalah plot progresif. Penokohan tokoh utama Sasaki Miyo adalah susah ditebak dan suka bertingkah tegar, sementara penokohan tokoh Hinode Kento adalah kurang percaya diri dan tertutup. Tema atau gagasan utama dari film anime Nakitai Watashi wa Neko wo Kaburu adalah kisah seorang gadis SMP yang tidak bahagia memilih untuk lari dan berubah menjadi kucing. Amanat dari film anime Nakitai Watashi wa Neko wo Kaburu adalah bagaimana kita terkadang tidak menyadari hal-hal baik di sekitar kita sampai hal tersebut terancam hilang selamanya, dan juga 
pentingnya mengutarakan apa yang ingin kita katakan pada seseorang sebelum kesempatan itu hilang dan kita menyesalinya seumur hidup kita. Latar tempat film anime Nakitai Watashi wa Neko wo Kaburu adalah Tokoname, Prefektur Aichi, Jepang. Latar waktunya adalah pada saat musim panas, dan latar sosialnya adalah kebiasaan Orang Jepang dalam ikut merayakan berbagai macam festival pada saat musim panas dan bagaimana beberapa masyarakat Jepang mengandalkan anak laki-laki untuk menafkahi keluarga.

Analisis yang dilakukan menggunakan teori psikoanalisis Freud menunjukkan berbagai hasil bagaimana konflik batin dan mekanisme pertahanan tokoh Sasaki Miyo. Id dalam diri Miyo adalah dorongan keinginannya untuk mendekati Hinode, dan dorongan rasa marahnya karena orang tuanya yang bercerai. Miyo yang berada di tengah situasi dimana orang tuanya baru saja bercerai dan merasa kesal akan hal tersebut, mendapati dirinya gagal mendekati Hinode dan dibenci oleh Hinode setelah mencoba memberikan surat cinta kepada Hinode. Saat impuls atau dorongan keinginannya tidak ada yang tercapai, maka egonya mencoba berbagai mekanisme pertahanan untuk beradaptasi. Salah satunya yaitu kompensasi dimana muncul id baru untuk menggantikan id sebelumnya yang tidak terpenuhi, yaitu keinginan baru untuk menjadi kucing. Selain kompensasi, ego Miyo mencoba berbagai mekanisme pertahanan untuk beradaptasi dan melindunginya dari id atau dorongan yang dianggap berbahaya, seperti rasionalisasi dan reaction formation. Rasionalisasi dilakukan pada saat ego Miyo memilih untuk mendengarkan superegonya dalam mengumpulkan informasi tentang Hinode dan menahan id yang ingin mendekati Hinode. Reaction formation yaitu pada saat id atau dorongan untuk memprojeksikan rasa marahnya kepada Kaoru muncul dan Miyo justru bertingkah ramah terhadap Kaoru agar dapat hidup dengan damai. Saat id atau dorongan rasa marahnya sudah tidak dapat diterima, egonya akhirnya memilih untuk melakukan projeksi, yaitu pada saat Miyo marah kepada ibunya saat festival dan pada saat Kaoru meragukan Miyo yang selalu bersikap ceria. Pada saat melakukan projeksi terhadap Kaoru, ego Miyo juga melakukan reversal karena sebelum projeksi egonya melakukan reaction formation. Yang terakhir, ego Miyo memilih untuk melakukan mekanisme pertahanan undoing, dimana Miyo mencoba menutupi kesalahan yang diperbuat karena egonya mengikuti id dalam memprojeksikan dorongan amarahnya dan juga mengikuti keinginan untuk menjadi kucing. Setelah berubah menjadi Tarou dan sadar kalau ia tidak dapat kembali, superego Miyo muncul dari penyesalan dan membuat ego memilih untuk mengikuti superegonya untuk memperbaiki kesalahannya dan kembali menjadi manusia.

\section{DAFTAR PUSTAKA}

Abrams, M. H. (1988). A Glossary of Literary Terms: 5th Edition. New York: Holt, Rinehart And Winston, Inc.

Alwisol. (2018). Psikologi Kepribadian. Malang: UMM Press.

Clements, J. (2017). Anime: A History. NY: Bloomsburry Publishing.

Cramer, P. (2006). Protecting the Self. New York: The Guilford Press.

Davey, G. (2012). Complete Psychology Second Edition. New York: Routledge.

Endarswara, S. (2011). Metodologi Penelitian Sastra: Epistemologi,Mode, Teori, dan Aplikasi. Yogyakarta: Pustaka Widyatama.

Forster, E. M. (2002). Aspects of the Novel. New York: Rosetta Books.

Freud, A. (1993). The Ego and The Mechanism of Defense. Terjemahan oleh Cecil Baines. London: Karnac Books.

Freud, S. (2011). Group Psychology and The Analysis of The Ego. Terjemahan oleh James Strachey. University of Michigan.

Freud, S. (1989). The Ego and The Id. New York, W.W. Norton \& Company.

Gabbard, G, O. (2004). Long-Term Psychodinamic Psychotherapy: A Basic Text. London: American Psychiatric Publishing, Inc.

Hall, C. S \& Lindzey, G. (1993). Teori-teori Psikodinamik (klinis). Yogyakarta: kanisius.

Hariyanti, A. S., Rahmah, Y., Fadli, Z. A. (2016). Konflik Batin Tokoh Akira Sakamoto 
Dalam Manga Family Complex Karya Mikiyo Tsuda. Jurnal Japanese Literature, 2(1), 112.

KBBI, 2009. Kamus Besar Bahasa Indonesia (KBBI). Pusat Bahasa Departemen Pendidikan Nasional.

Klarel, M. (1999). An Introduction to Literary Studies. New York: Routledge.

Mahsun. 2014. Metode Penelitian Bahasa. Depok: Rajawali Pers.

Martono, N., Rosa., H. T., Azmin, G. G. (2016). Mekanisme Pertahanan Ego Pada Tokoh Transgender Dalam Novel Pasung Jiwa Karya Okky Madasari: Suatu Kajian Psikologi Sastra. Arkhais, 7(2), 1-6.

Minderop, A. (2010). Psikologi Sastra. Jakarta: Yayasan Pustaka Obor Indonesia.

Nurgiyantoro, B. (2002). Teori Pengkajian Fiksi. Yogyakarta: Gadjah Mada University Press.

Schacter, D. L., Gilbert, D. T., Wegner, D. M. (2010). Psychology: Second Edition. New York: Worth Publishers.

Sherrer, G. B. (1941). Literature in a Changing World. The English Journal, 30(8), 1.
Sugiyono. (2015). Metode Penelitian Pendidikan (Pendekatan Kuantitatif, Kualitatif, dan $R \& D)$. Bandung: Anggota Ikatan Penerbit Indonesia (IKAPI).

Taylor, S. J., \& Bogdan, R. (2016). Introduction to Qualitative Research Methods. New Jersey: JohnWiley \& Sons, Inc.

Waslam. (2015). Kepribadian Dalam Teks Sastra: Suatu Tinjauan Teori Sigmund Freud. Jurnal Pujangga, 1 (2), 138-154.

Wellek, R., \& Warren, A. (1956). Theory of Literature: Third Edition. San Diego: Harcourt, Brace, and Company.

\section{PUSTAKA LAMAN}

Ben, $\mathrm{K}$. "You can now visit the setting of " $A$ Whisker Away" in Tokoname, Aichi Prefecture", [online], (https://grapee.jp/en/145286, diakses tanggal 3 November 2020) . "31 Psychological Defense Mechanisms Explained", [online], (https://www.psychologistworld.com/fr eud/defence-mechanisms-list, diakses tanggal 22 November 2020) 